\title{
Investigation of Pore Size Effect On Spray Cooling Heat Transfer With Porous Tunnels
}

\author{
ERIC A. SILK \\ Thermal Engineering Technology Development Group \\ NASA Goddard Space Flight Center, Greenbelt, MD 20771, USA \\ Tel(301)-286-5534;Email: Eric.A.Silk@nasa.gov
}

\begin{abstract}
Previous studies have shown that spray cooling heat flux enhancement may be attained by using enhanced surface structures. However, most enhanced surface spray cooling studies have been limited to extended surfaces relative to the base surface. In this study, experiments were conducted to study the effects of pore size on spray cooling heat flux when using porous tunnels. The porous tunnels where placed sub-surface relative to the top of the heater block. Pores of varying size were machined in the top of the heater block leading into the sub-surface tunnels. Pore diameters varied between $0.25 \mathrm{~mm}$ and $1.0 \mathrm{~mm}$. Each copper block had a projected cross-sectional area of $2.0 \mathrm{~cm}^{2}$. Measurements were also obtained on a heater block with a flat surface for baseline comparison purposes. A $2 \times 2$ nozzle array was used with PF-5060 as the working fluid. Thermal performance data was obtained under nominally degassed (chamber pressure of $41.4 \mathrm{kPa}$ ) conditions with a bulk fluid temperature of $20.5^{\circ} \mathrm{C}$. Results for both the study show that the highest critical heat flux (CHF) attained was $141 \mathrm{~W} / \mathrm{cm}^{2}$ using pores $1.0 \mathrm{~mm}$ in diameter. This gave an enhancement of $75 \%$ relative to the flat surface case under nominally degassed conditions.
\end{abstract}

Keywords: spray cooling, enhanced surfaces, heat transfer

\section{INTRODUCTION}

A great deal of research has been conducted to gain a better understanding of the general phenomena and critical parameters associated with spray cooling heat transfer. A review of the literature shows that previous studies have parametrically examined the effect of secondary gas atomizers vs. pressure atomizers $[1,2]$, mass flux of ejected fluid [3,4], spray velocity [5,6], surface impact velocity $[5,7,8]$, surface roughness $[1,6,9,10]$, ejected fluid temperature, chamber environmental conditions, and spray footprint optimization on the effective heat flux across the heater surface [11]. Other topics studied to date include the effect of surfactant addition [12,13], and secondary nucleation $[1,14,15]$.

Most previous studies that have examined enhanced surfaces have done so primarily from the perspective of surface roughness. Sehmbey et al. [1] gives an overview of spray cooling and provides a comparison of its effectiveness when using liquid and secondary gas atomizers (air used as the secondary gas). Heat flux was measured and presented for both techniques. Both the heat flux and the convection coefficient were found to have comparable values for both atomizer types. The authors concluded that the most important parameters affecting heat transfer are the fluid properties, spray velocity and surface conditions. It was also found that the heat transfer coefficient increased with the use of smooth surfaces $\left(R_{a}<0.1 \mu \mathrm{m}\right)$ for gas atomized sprays, while the opposite trend was observed for liquid atomized sprays.

Pais et al. [10] also studied the effects of surface roughness on heat transfer when using spray cooling. The scales of the surface roughness studied were 22,14 and $0.3 \mu \mathrm{m}$. The sprayed surface was copper with a projected area of $1 \mathrm{~cm}^{2}$. An air-assist atomizing nozzle was used with deionized water as the working fluid. Tests were conducted at a nozzle height of $23 \mathrm{~mm}$. Tests were run up to CHF for all surface roughness values. It was found that the $0.3 \mu \mathrm{m}$ surface achieved the highest heat flux, with a peak heat flux of 1250 $\mathrm{W} / \mathrm{cm}^{2}$. Furthermore, the onset of nucleate boiling was experienced at lower superheat values. The authors attributed the heat transfer enhancement to early bubble departure from the surface and nucleate boiling. The authors also concluded that secondary nucleation has a primary role as a heat transfer mechanism only if the surface finish is smooth.

Silk et al. [16] investigated the effects of enhanced surface structures beyond the surface roughness range on spray cooling heat transfer. The surface enhancements consisted of cubic pin fins, pyramids, and straight fins machined on the top surface of heated copper blocks with $2.0 \mathrm{~cm}^{2}$ cross-sectional areas. Measurements were also obtained on a heated flat surface for data comparison. PF-5060 under nominally 
degassed conditions (chamber pressure of $41.4 \mathrm{kPa}$ ) was used as the working fluid. Spray volumetric flux $\left(0.016 \mathrm{~m}^{3} / \mathrm{m}^{2} \mathrm{~s}\right)$ and nozzle to heater distance $(17 \mathrm{~mm})$ were held constant throughout each test. The spray temperature was $20.5^{\circ} \mathrm{C}$. The study showed that the straight fins had the largest heat flux enhancement relative to the flat surface, followed by the cubic pin fins and the pyramid surface. Each surface had an increase in evaporation efficiency at CHF compared to the flat surface. However, $\eta_{2-\Phi}<50 \%$ in each case which suggested that the process is single phase dominated. The authors determined that the straight finned surface had the most efficient use of area added for additional heat transfer relative to the flat surface. They also determined that heat flux enhancement observed with the use of enhanced surfaces is a function of surface area added and liquid management on the heater surface.

Much work has been performed on pool boiling using enhanced surfaces. Surface modifications previously investigated include the use of paints, porous structures, and structured surface geometries (macro, micro and submicron-scale). Each of these techniques has been shown to enhance heat transfer given certain application constraints.

Pool boiling has received much attention regarding heat flux enhancement applications. These applications have been implemented through surfaces designed to increase nucleation site density and/or addition of surface area available for nucleation. Enhancements such as paints and porous structures may be considered as providing heat flux enhancement through increased nucleation sites. Structured surface geometries (macro, micro and submicron-scale) provide heat flux enhancement through both. Each of these techniques have been shown to enhance heat transfer for certain applications.

The study by Chien and Webb [17] investigated the impact of pore diameter and pitch for structured tunnels upon nucleate boiling of R-11 and R-123. The pore diameters studied were $0.12 \mathrm{~mm}, 0.18 \mathrm{~mm}$, $0.23 \mathrm{~mm}$, and $0.28 \mathrm{~mm}$. Pitch dimensions used were $1.5 \mathrm{~mm}$ and $3.0 \mathrm{~mm}$. The heat fluxes for this study ranged between $2 \mathrm{~kW} / \mathrm{m}^{2}$ and $70 \mathrm{~kW} / \mathrm{m}^{2}$. The authors found that the liquid supply rate to the tunnel was a function of the pore diameter. They concluded that as the pore diameter increased, the tunnel dry-out heat flux increased as well. However, the large pore surfaces exposed to low heat fluxes $\left(\leq 35 \mathrm{~kW} / \mathrm{m}^{2}\right)$ produced flooding and thereby lowered the convection coefficient. Smaller pores could not provide sufficient liquid into the tunnel when exposed to high heat flux. This case also produced low convection coefficients.

Rainey et al. [18] conducted a flow boiling study on plain and micro-porous coated surfaces. The working fluid used was FC-72. Two copper heaters were used, each with a $1.0 \mathrm{~cm}^{2}(10 \mathrm{~mm} \times 10 \mathrm{~mm})$ heat exchange surface area. One was highly polished, while the other was micro-porous coated. The coated surface had a fine porous structure with cavity feature sizes ranging 0.1 to $1.0 \mu \mathrm{m}$ and $50 \mu \mathrm{m}$ thick. The coating material used was Aluminum/Brushable Ceramic epoxy/Methyl-Ethyl-Ketone. During testing, both surfaces were mounted to the bottom of a horizontal flow channel. Channel velocities tested ranged $0.5 \mathrm{~m} / \mathrm{s}$ to $4.0 \mathrm{~m} / \mathrm{s}$ with subcooling on the order of $4 \mathrm{~K}$ to $20 \mathrm{~K}$. Nucleate boiling on the smooth surface was shown to be highly dependent on flow velocity (which ranged between $0-0.5 \mathrm{~m} / \mathrm{s}$ ) and subcooling up to $4 \mathrm{~K}$. The micro-porous surface (relative to the smooth surface) showed enhancement factors up to 1.5 with the exception of the high heat flux regime. Above $50 \mathrm{~W} / \mathrm{cm}^{2}$, the micro-porous surface actually provided worse heat transfer performance than the smooth surface.

The initial work by Silk et al. [19] showed that spray cooling of embedded surface structures such as dimples and porous tunnels results in a corresponding heat flux enhancement. The present work extends the investigation of embedded structures. Spray cooling heat flux as a function of pore size for a fixed tunnel structure is reported. Three geometries were tested for heat flux comparison between one another as well as comparison to the flat surface case. The surfaces tested included pores ranging $0.25 \mathrm{~mm}$ to $1.0 \mathrm{~mm}$ in diameter. It was found that CHF for the pt_0.5 and pt_1.0 surfaces was greater than that of the flat surfaces throughout the flow rates tested.

\section{TEST SETUP AND PROCEDURE}

The experiments were conducted using a closed fluid loop system. The test rig (schematic shown in Fig. 1) consisted of an environmental test chamber, liquid pump, flow meter, micro-filter and a condenser. Chamber temperature and pressure were measured via a T-type thermocouple and a pressure sensor. Temperature and pressure sensors were also placed in the liquid line upstream of the nozzle for fluid and supply line temperature and pressure measurement.

Heat was supplied to the test article using a $500 \mathrm{~W}$ cartridge heater. The test article was placed within the interior of the chamber, but was separated from the excess liquid by an enclosure consisting of a polycarbonate housing and an alumina bisque ceramic top flange (Fig. 2). The upper section of the copper 
block was epoxied to the ceramic flange. Temperature measurements in the copper blocks were taken via five T-type thermocouples mounted in the upper section of each block (Fig. 3). Assuming steady state 1-D conduction through the upper portion of the block, the heat flux was calculated using Fourier's Law. Reported heat flux was determined as the average value from multiple pairs

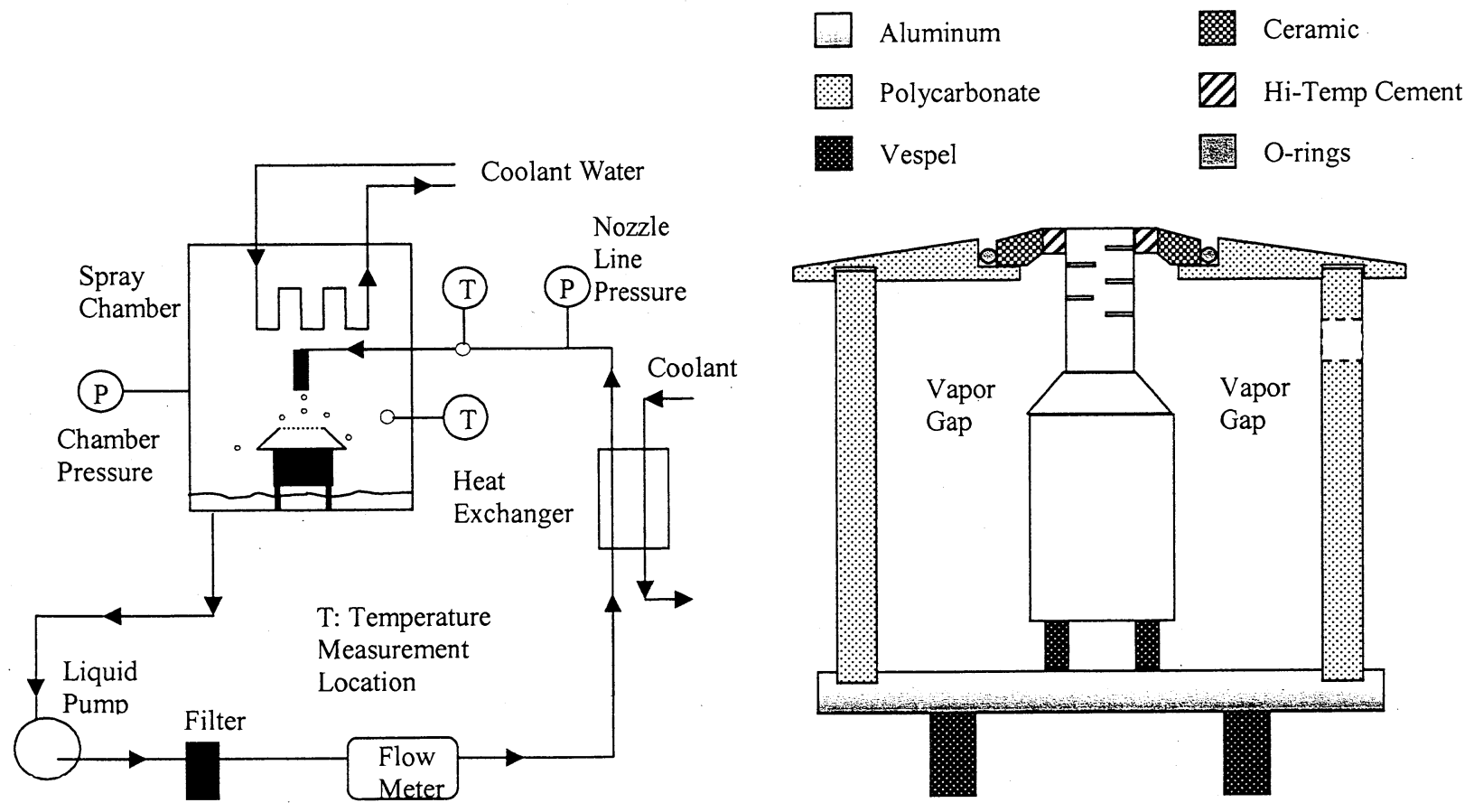

Figure 1. Spray cooling test rig configuration

Figure 2. Copper block housing schematic

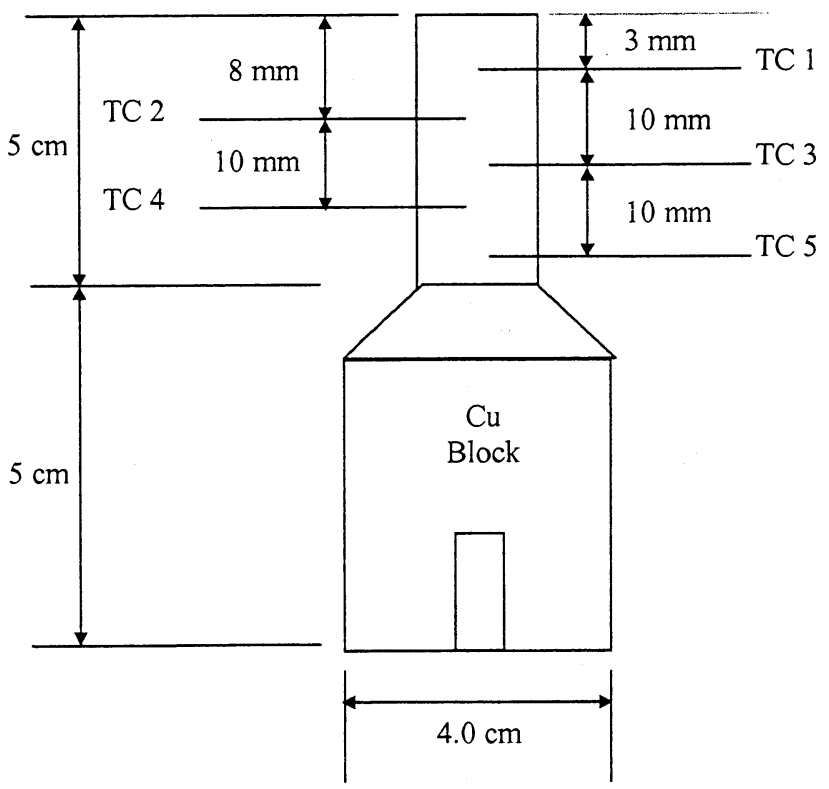

Figure 3. Copper block schematic with TC locations (not to scale) 
Table 1. Test case conditions

\begin{tabular}{|c|c|}
\hline \multicolumn{2}{|c|}{ Spray Cooling Parameters } \\
\hline Parameters & Degassed Case \\
\hline $\mathrm{P}_{\text {sat }}$ & $41.4 \mathrm{kPa}$ \\
\hline $\mathrm{T}_{\mathrm{sat}}$ & $31^{\circ} \mathrm{C}$ \\
\hline $\mathrm{T}_{1}$ & $20.5^{\circ} \mathrm{C}$ \\
\hline $\mathrm{h}_{\mathrm{fg}}$ & $92 \mathrm{~kJ} / \mathrm{kg}$ \\
\hline Gas Content & $470 \mathrm{ppm}$ \\
\hline
\end{tabular}

of thermocouples (TC1 through TC5). Surface temperature was determined via linear extrapolation using TC1 and TC2.

Prior to each test, the spray chamber and fluid loop were charged with PF-5060. A vacuum was repeatedly applied to the chamber until a pressure of $41.4 \mathrm{kPa}$ (470 ppm gas concentration) was reached. The chamber was allowed to attain equilibrium prior to conducting the tests. Test conditions are shown in Table 1.

All tests were run at constant chamber pressure and constant nozzle-to-heater surface distance. Flow rates tested ranged $120 \mathrm{ml} / \mathrm{min}$ to $200 \mathrm{ml} / \mathrm{min}$. Heat was supplied to the cartridge heater in increments of 10 W using a programmable power supply. Steady state was achieved at each power level, and data was acquired before application of the next successive heat load. Upon dry-out (detected by a rapid increase in surface temperature and a rapid decrease in heat flux), power to the cartridge heater was turned off.

A Parker Hannifin prototype spray nozzle consisting of a $2 \times 2$ spray cone array was used for each of the tests. Prior to heat flux testing, the spray nozzle uniformity was measured using stainless steel tubes of varying inner diameters, a graduated cylinder, and a stopwatch. The largest tube had an inner diameter approximately the same diameter as the heated surface. Size, local volume flux between concentric cylinders, and the local volume flux between concentric cylinders normalized by the average volume flux over the entire heater surface $(\Gamma)$ are shown in Fig. 4 . A $\Gamma$ value of unity indicates that the local volume flux is identical to the total volume flux averaged across the entire heater surface. The volume flux was largest towards the center of the heater region. The center ring $\left(A_{1}\right)$ had twice as much volume flux as the average for the entire area while the outer ring $\left(\mathrm{A}_{4}\right)$ was sprayed by a volume flux that was only $40 \%$ of the average area value. Given the volume flux variation throughout the concentric rings, the spray can be considered a non-uniform center biased spray for the current nozzle height and heater area. Spray characteristics were not investigated.

\begin{tabular}{|c|c|c|c|c|}
\hline Section & $\begin{array}{c}\text { Area } \\
\left(\mathbf{c m}^{\mathbf{2}}\right)\end{array}$ & $\begin{array}{c}\text { Area } \\
(\%)\end{array}$ & $\begin{array}{c}\text { Vol. Flux } \\
\left(\mathbf{m}^{\mathbf{3}} / \mathbf{m}^{\mathbf{2}} \mathbf{~ s}\right)\end{array}$ & $\boldsymbol{\Gamma}_{\mathbf{i}}$ \\
\hline $\mathrm{A}_{1}$ & 0.33 & 17.5 & 0.026 & 2.0 \\
\hline $\mathrm{A}_{2}$ & 0.38 & 20.0 & 0.024 & 1.8 \\
\hline $\mathrm{A}_{3}$ & 0.54 & 28.5 & 0.007 & 0.6 \\
\hline $\mathrm{A}_{4}$ & 0.64 & 34.0 & 0.005 & 0.4 \\
\hline
\end{tabular}

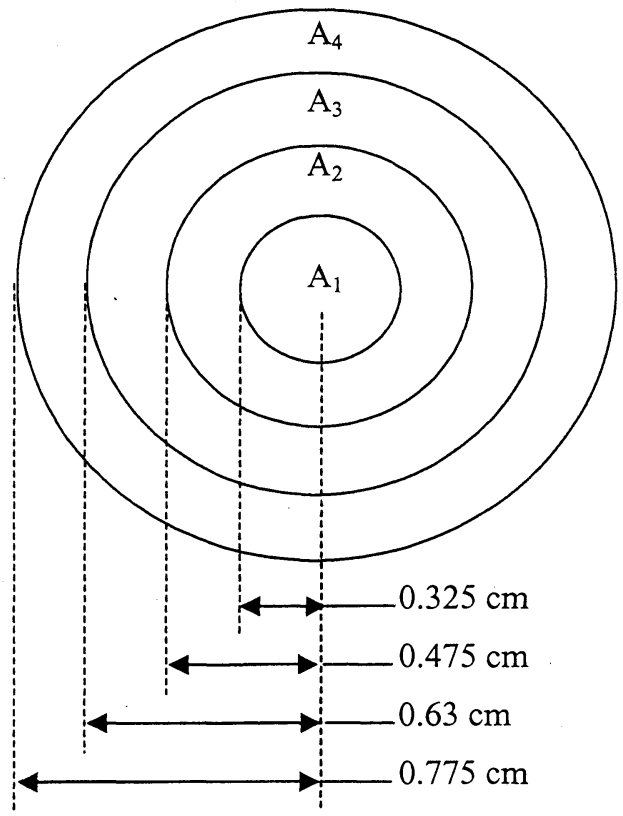

Figure 4. Spray uniformity test schematic (not to scale) 
The pore and tunnel dimensions of each surface are summarized in Table 2. A schematic and photographs of the enhanced surfaces are shown in Fig. 5. The subsurface tunnels were aligned along a single axis. The centerline of each tunnel was positioned beneath a row of pores drilled normal to the surface. Each tunnel extended through the entire cross section of the copper block. The perimeter of that cross section (including the areas immediately circumscribing the perimeter of the tunnel outlets) was insulated with high temperature cement. This limited liquid contact to the top surface, the pore interior, and the interior of the tunnels. Pore density and tunnel dimensions were constant for each of the surfaces tested. Pore diameters investigated were $0.25 \mathrm{~mm}, 0.5 \mathrm{~mm}$ and $1.0 \mathrm{~mm}$.

Table 2. Enhanced surface geometry summary

\begin{tabular}{|c|c|c|c|c|}
\hline \multirow{2}{*}{ Surface } & \multicolumn{4}{|c|}{ Dimensions in (mm) } \\
\cline { 2 - 5 } & $\mathrm{L}$ & $\mathrm{d} 1$ & $\mathrm{~d} 2$ & $\mathbf{z 1}$ \\
\hline Flat Surface (1f) & 0 & -- & -- & -- \\
\hline $1.0 \mathrm{~mm}$ Porous Tunnels (pt_1.0) & 1.0 & 1.0 & 1.0 & 0.5 \\
\hline $0.5 \mathrm{~mm}$ Porous Tunnels (pt_0.5) & 1.5 & 0.5 & 1.0 & 0.5 \\
\hline $0.25 \mathrm{~mm}$ Porous Tunnels (pt_0.25) & 1.75 & 0.25 & 1.0 & 0.5 \\
\hline
\end{tabular}

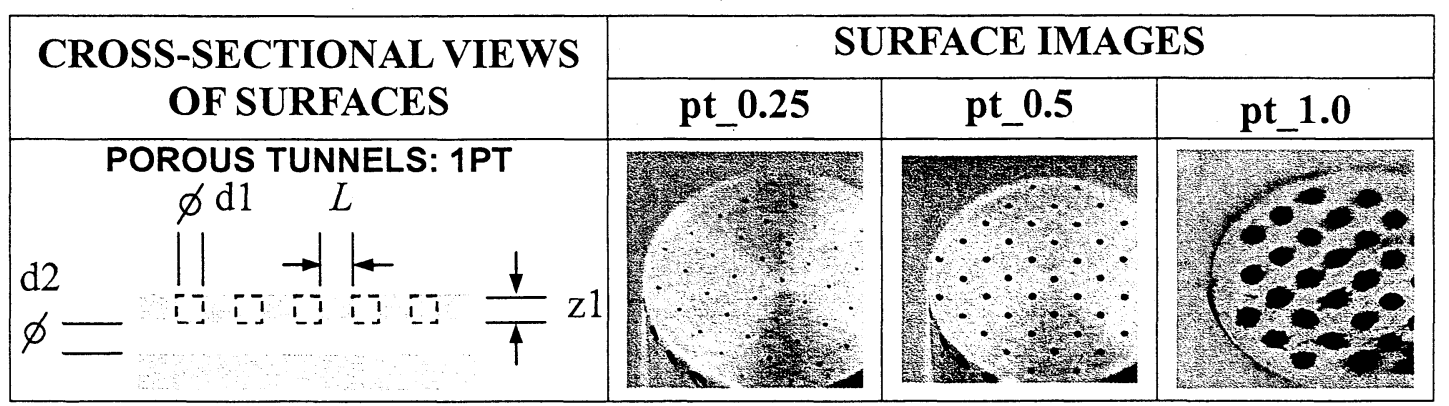

Figure 5. Surface geometry cross sectional views and photos

\section{MEASUREMENT UNCERTAINTY}

The primary quantity of interest for these experiments is the heat flux. The heat flux calculation has three primary contributions to the uncertainty: the conductivity, the thermocouple locations, and the error in the temperature measured. The conductivity value used was $389 \mathrm{~W} / \mathrm{m} \mathrm{K}$ with an estimated error of $1 \%$. The error in the thermocouple temperature measurements was estimated as $\pm 0.5^{\circ} \mathrm{C}$. The error in the thermocouple location was determined to be $\pm 0.56 \mathrm{~mm}$. Equation 1 was used to calculate the error for the heat flux values reported. The uncertainty in the heat flux was determined to be $5.6 \%$ at $80 \mathrm{~W} / \mathrm{cm}^{2}$. Calculations indicated that heat losses within the upper neck of the copper block were less than $1 \%$ of the total heat input at $\mathrm{CHF}$ for the flat surface case. Spray cooling heat flux demonstrated repeatability within $1 \%$ for multiple tests under identical test conditions. Pressure values had an uncertainty of $\pm 3 \mathrm{kPa}$. Flow meter measurements had an error of $\pm 1 \mathrm{ml} / \mathrm{min}$.

$$
\delta \dot{q}^{\prime \prime}= \pm \sqrt{\left(\frac{\partial \dot{q}^{\prime \prime}}{\partial x} \delta_{x}\right)^{2}+\left(\frac{\partial \dot{q}^{\prime \prime}}{\partial k} \delta_{k}\right)^{2}+\left(\frac{\partial \dot{q}^{\prime \prime}}{\partial(\Delta T)} \delta_{\Delta T}\right)^{2}}
$$




\section{RESULTS AND DISCUSSION}

Heat flux performance as a function of the structure geometry for each of the surfaces is shown in Figs. 6 and 7. The calculated heat flux is based on the projected area $\left(2.0 \mathrm{~cm}^{2}\right)$ for all cases (not the wetted surface area exposed to the fluid).

\section{Flat Surface (1f)}

Fig. 6 shows heat flux as a function of surface temperature for the flat surface cases. Volumetric fluxes tested ranged $0.010 \mathrm{~m}^{3} / \mathrm{m}^{2}-\mathrm{s}(120 \mathrm{ml} / \mathrm{min})$ to $0.016 \mathrm{~m}^{3} / \mathrm{m}^{2}-\mathrm{s}(200 \mathrm{ml} / \mathrm{min})$. The heat transfer variation for all volumetric fluxes is linear in the low heat flux regime, which is indicative of single phase convection. Multiphase effects become pronounced (denoted by the increase in slope of the heat flux curves) for the lower volumetric flux cases (i.e., volumetric fluxes of 0.010 and $0.011 \mathrm{~m}^{3} / \mathrm{m}^{2}-\mathrm{s}$ ) around $\mathrm{T}_{\text {surf }} \approx 45^{\circ} \mathrm{C}$. For the other flow rate cases, multiphase effects become pronounced between $\mathrm{T}_{\text {surf }} \approx 50^{\circ} \mathrm{C}$ and $52^{\circ} \mathrm{C}$. There is a noticeable increase in heat flux throughout the spray cooling curves as the volumetric flux increases from $0.010 \mathrm{~m}^{3} / \mathrm{m}^{2}$-s to $0.016 \mathrm{~m}^{3} / \mathrm{m}^{2}$-s. However, the $0.015 \mathrm{~m}^{3} / \mathrm{m}^{2}$-s and $0.016 \mathrm{~m}^{3} / \mathrm{m}^{2}$-s cases have spray cooling curves that are nearly identical (i.e., well within the experimental uncertainty). This indicates that for the test conditions used, volumetric fluxes greater that $0.015 \mathrm{~m}^{3} / \mathrm{m}^{2}$-s provide diminishing returns upon the heat flux. The maximum CHFs $\left(79 \mathrm{~W} / \mathrm{cm}^{2}\right.$ and $\left.80 \mathrm{~W} / \mathrm{cm}^{2}\right)$ occurred for the $0.015 \mathrm{~m}^{3} / \mathrm{m}^{2}-\mathrm{s}$ and $0.016 \mathrm{~m}^{3} / \mathrm{m}^{2}-\mathrm{s}$ cases respectively.

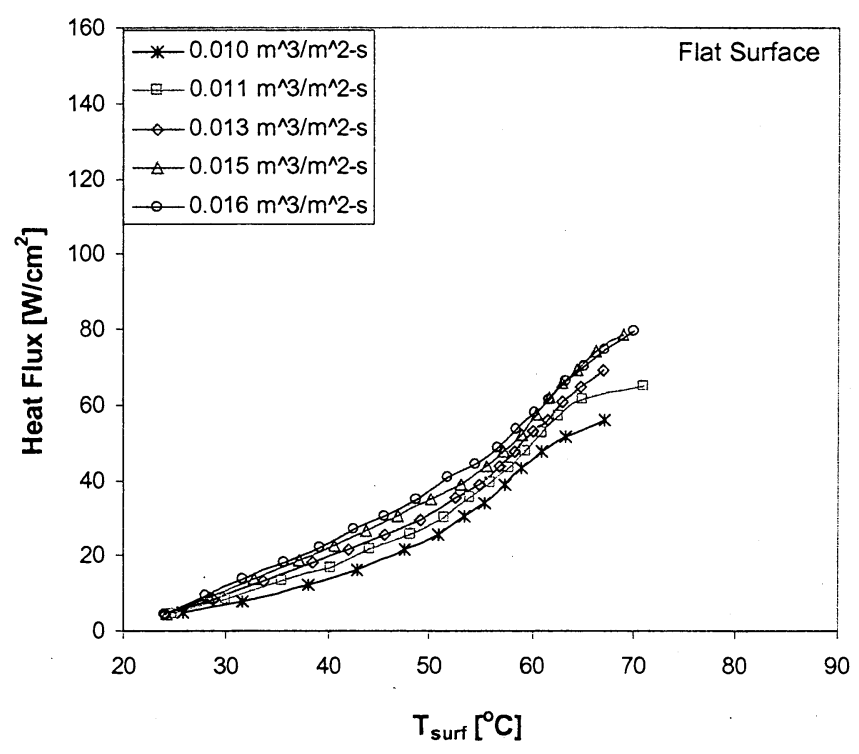

Figure 6. Heat flux as a function of surface temperature for Flat surface

\section{Porous Tunnel Surfaces (pt_0.25, pt_0.5 and pt_1.0)}

Figs. $7 \mathrm{a}$ through $7 \mathrm{c}$ show heat flux as a function of surface temperature for porous tunnel cases pt 0.25 , pt 0.5 and pt 1.0 respectively. Volumetric fluxes tested ranged $0.010 \mathrm{~m}^{3} / \mathrm{m}^{2}-\mathrm{s}(120 \mathrm{ml} / \mathrm{min})$ to 0.016 $\mathrm{m}^{\frac{3}{3}} / \mathrm{m}^{2}-\mathrm{s}(200 \mathrm{ml} / \mathrm{min})$. Similar to the flat surface case, heat transfer variation for all volumetric fluxes in figures $7 \mathrm{a}$ through $7 \mathrm{c}$ are linear in the low heat flux regime. For surface pt_ 0.25 (shown in figure $7 \mathrm{a}$ ), multiphase effects do not become pronounced until $\mathrm{T}_{\text {surf }} \approx 60^{\circ} \mathrm{C}$ whereas for surfaces pt_0.5 and pt_1.0 (shown in figures $7 \mathrm{~b}$ and $7 \mathrm{c}$ respectively), multiphase effects become pronounced around $\mathrm{T}_{\text {surf }} \approx 45^{\circ} \mathrm{C}$. Heat flux increased with volumetric flux for each of the porous tunnel surfaces tested. Porous tunnel surfaces pt_0.5 and pt_1.0 performed better than the flat surface at each of the volumetric fluxes tested. However, surface pt_0.25 displayed heat flux performance slightly less than that for the flat surface at volumetric fluxes between $0.010 \mathrm{~m}^{3} / \mathrm{m}^{2}$-s and $0.015 \mathrm{~m}^{3} / \mathrm{m}^{2}$-s. Maximum CHF for the porous tunnel surfaces studied was $141 \mathrm{~W} / \mathrm{cm}^{2}$ for surface pt_1.0. Surfaces pt_0.25 and pt_0.5 each had a maximum CHF of $84 \mathrm{~W} / \mathrm{cm}^{2}$ and $124 \mathrm{~W} / \mathrm{cm}^{2}$ respectively at a volumetric flux of $0.016 \mathrm{~m}^{3} / \mathrm{m}^{2}-\mathrm{s}$. 


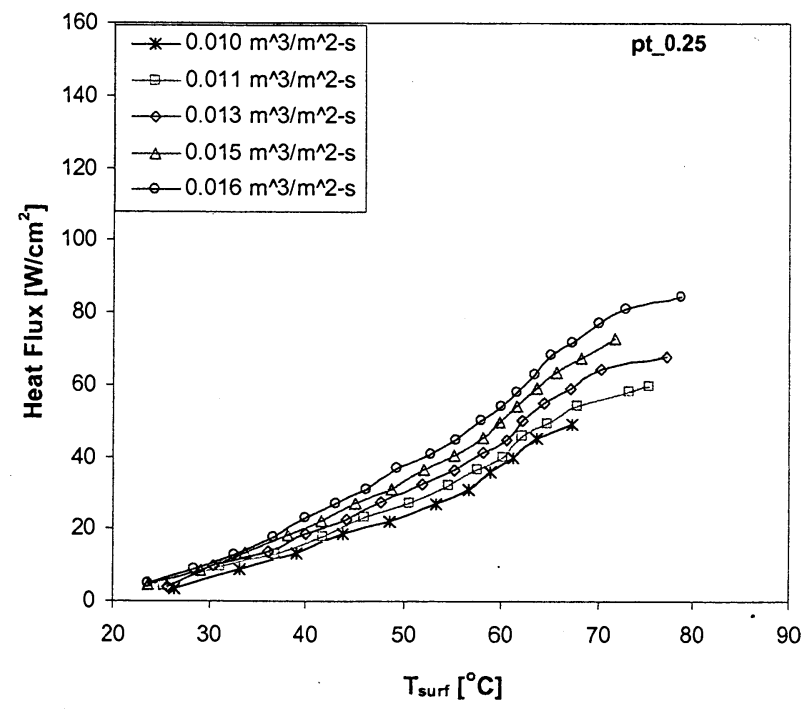

(a)

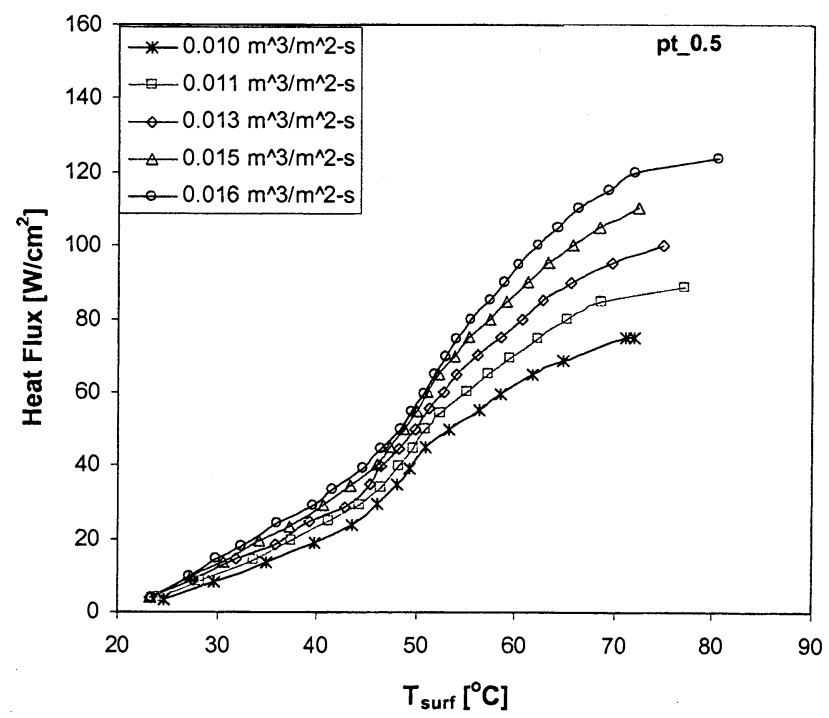

(b)

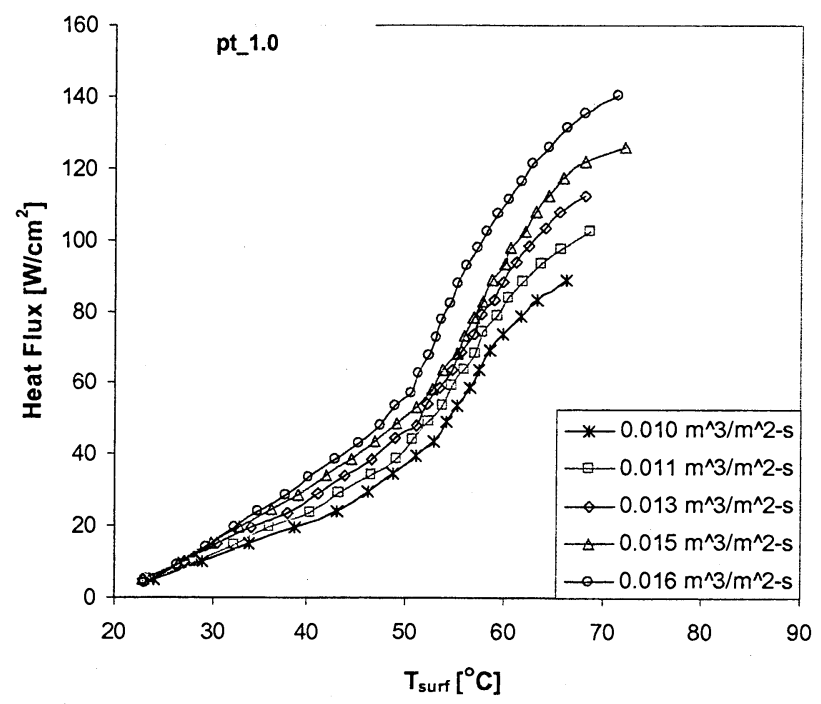

(c)

Figure 7. Heat flux as a function of surface temperature and volumetric flux for Porous tunnel surfaces; (a) pore diameter of $0.25 \mathrm{~mm}$, (b) pore diameter of $0.5 \mathrm{~mm}$, (c) pore diameter of $1.0 \mathrm{~mm}$

\section{Effects of Pores and Tunnels}

Spray cooling is considered a multiphase convective process. Convective heat transfer processes are typically defined using Newton's Law of Cooling where the heat transfer has functional dependence upon the convection coefficient, the heat exchange surface area and the surface to liquid temperature difference [i.e., $\dot{q}=\dot{q}\left(\mathrm{~h}_{\text {conv }}, \mathrm{A}_{\text {surf, }} \mathrm{T}_{\text {surf }} \mathrm{T}_{1}\right)$ ]. While the heat flux calculated for the structured tunnel surfaces was based on the projected surface area (i.e., $2.0 \mathrm{~cm}^{2}$ ), the addition of the pore and tunnel side wall surface area provided additional area available for heat transfer. This also has benefit when using mutli-nozzle array 
systems displaying stagnation zone phenomena on the heater surface. Figures $8 \mathrm{a}$ and $8 \mathrm{~b}$ show photos of the flat and $1.0 \mathrm{~mm}$ pore surface (pt_1.0) for a volumetric flux of $0.010 \mathrm{~m}^{3} / \mathrm{m}^{2}-\mathrm{s}$. The flat surface (shown in Fig. 8a) clearly shows the development of a liquid dome due to stagnation zone phenomena. However, in the $1.0 \mathrm{~mm}$ pore case (Fig. $8 \mathrm{~b}$ ) the excess liquid on the heater surface has receded into the tunnel structure. Thus the tunnels provide both a structural relief and additional heat exchange area for excess liquid on the heater surface.

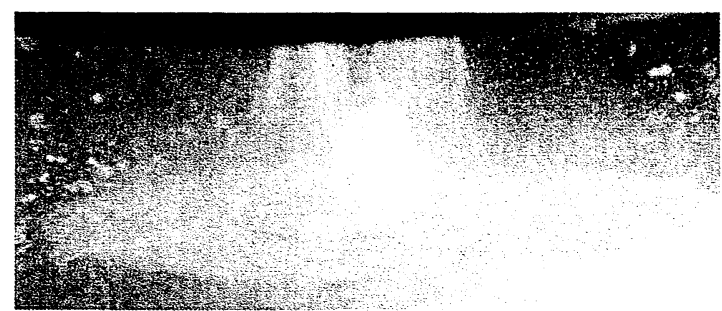

(a)

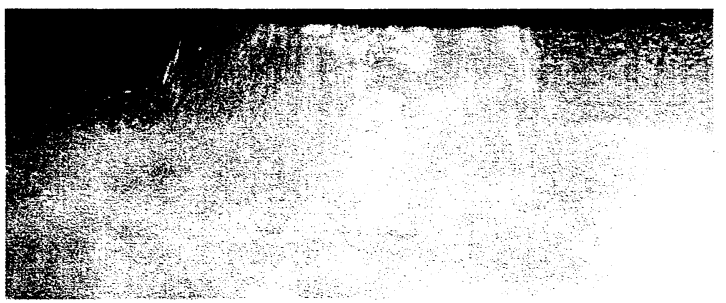

(b)

Figure 8. In-Situ photos of heater surface phenomena for a volumetric flux of $0.010 \mathrm{~m}^{3} / \mathrm{m}^{2}-\mathrm{s}$; (a) centerweighted spray with stagnation zone on flat surface, (b) Close-up of $1.0 \mathrm{~mm}$ porous tunnel surface with reduced liquid excess on heater surface

Table 3. Summary of Flat and Porous Tunnel Surface data

\begin{tabular}{|c|c|c|c|c|c|c|c|}
\hline Surface & Description & $\begin{array}{l}A_{\text {surf }} \\
\left(\mathrm{cm}^{2}\right)\end{array}$ & $\begin{array}{c}\text { Volumetric } \\
\text { Flux } \\
\left(\mathrm{m}^{3} / \mathrm{m}^{2}-\mathrm{s}\right)\end{array}$ & $\begin{array}{c}\dot{q}_{C H F}^{\prime \prime} \\
\left(\mathbf{W} / \mathrm{cm}^{2}\right)\end{array}$ & $\begin{array}{l}T_{\max } \\
\left({ }^{\circ} \mathrm{C}\right)\end{array}$ & $\begin{array}{l}\eta_{2-\Phi} \\
(\%)\end{array}$ & $\begin{array}{c}\text { Area } \\
\text { Utilization } \\
\text { Factor } \\
\xi_{2-\oplus}\end{array}$ \\
\hline $1 f$ & Flat Surface & 2.0 & 0.010 & 56 & 67.1 & 32.6 & $\ldots$ \\
\hline $1 f$ & Flat Surface & 2.0 & 0.011 & 65 & 70.9 & 34.4 & $\ldots$ \\
\hline $1 f$ & Flat Surface & 2.0 & 0.013 & 69 & 67.0 & 30.9 & $\ldots$ \\
\hline $1 f$ & Flat Surface & 2.0 & 0.015 & 79 & 69.0 & 30.6 & $\ldots$ \\
\hline $1 f$ & Flat Surface & 2.0 & 0.016 & 80 & 70.0 & 29.1 & $\cdots$ \\
\hline pt_0.25 & $0.25 \mathrm{~mm}$ pores & 5.29 & 0.010 & 49 & 67.3 & 28.5 & 0.33 \\
\hline pt_0.25 & $0.25 \mathrm{~mm}$ pores & 5.29 & 0.011 & 59 & 75.1 & 31.4 & 0.34 \\
\hline pt_0.25 & $0.25 \mathrm{~mm}$ pores & 5.29 & 0.013 & 68 & 77.0 & 30.2 & 0.37 \\
\hline pt_0.25 & $0.25 \mathrm{~mm}$ pores & 5.29 & 0.015 & 73 & 72.0 & 28.2 & 0.35 \\
\hline pt_0.25 & $0.25 \mathrm{~mm}$ pores & 5.29 & 0.016 & 84 & 79.0 & 30.6 & 0.40 \\
\hline pt_0.5 & $0.5 \mathrm{~mm}$ pores & 5.34 & 0.010 & 75 & 72.0 & 43.4 & 0.50 \\
\hline pt_0.5 & $0.5 \mathrm{~mm}$ pores & 5.34 & 0.011 & 89 & 77.0 & 46.8 & 0.51 \\
\hline pt_0.5 & $0.5 \mathrm{~mm}$ pores & 5.34 & 0.013 & 100 & 75.0 & 44.7 & 0.54 \\
\hline pt_0.5 & $0.5 \mathrm{~mm}$ pores & 5.34 & 0.015 & 110 & 72.4 & 42.6 & 0.52 \\
\hline pt_0.5 & $0.5 \mathrm{~mm}$ pores & 5.34 & 0.016 & 124 & 80.5 & 44.9 & 0.58 \\
\hline pt_1.0 & $1.0 \mathrm{~mm}$ pores & 5.14 & 0.010 & 89 & 66.3 & 51.5 & 0.62 \\
\hline pt_1.0 & $1.0 \mathrm{~mm}$ pores & 5.14 & 0.011 & 102 & 69.0 & 54.0 & 0.61 \\
\hline pt_1.0 & $1.0 \mathrm{~mm}$ pores & 5.14 & 0.013 & 112 & 68.0 & 50.3 & 0.63 \\
\hline pt_1.0 & $1.0 \mathrm{~mm}$ pores & 5.14 & 0.015 & 126 & 75.1 & 48.7 & 0.62 \\
\hline${ }^{\mp}$ pt_1.0 & $1.0 \mathrm{~mm}$ pores & 5.14 & 0.016 & 141 & 71.0 & 51.1 & 0.69 \\
\hline
\end{tabular}

denotes data previously published by Silk et al. [16] 
Table 3. is a summary of the data for the flat and porous tunnel surfaces. Included in the table is the surface area $\left(\mathrm{A}_{\text {surf }}\right)$, volumetric flux, $\mathrm{CHF}$, surface temperature at $\mathrm{CHF}\left(\mathrm{T}_{\max }\right)$, multiphase evaporation efficiency $\left(\eta_{2-\Phi}\right)$ and the multiphase area utilization factor $\left(\xi_{2-\Phi}\right)$. As shown in Table 3 , addition of the structured tunnels increased the total surface area available for heat transfer by slightly more than a factor of two (surface areas ranged $5.14 \mathrm{~cm}^{2}$ to $5.34 \mathrm{~cm}^{2}$ for the structured tunnel cases). Nonetheless, the benefit of the additional surface area is only achieved if a volume of the working fluid significant enough to effect the heat transfer actually reaches the tunnels. Fig. 9 is a plot of CHF as a function of pore size at different volumetric fluxes. In the plot, the flat surface is considered as having a pore size of $0 \mathrm{~mm}$. As mentioned

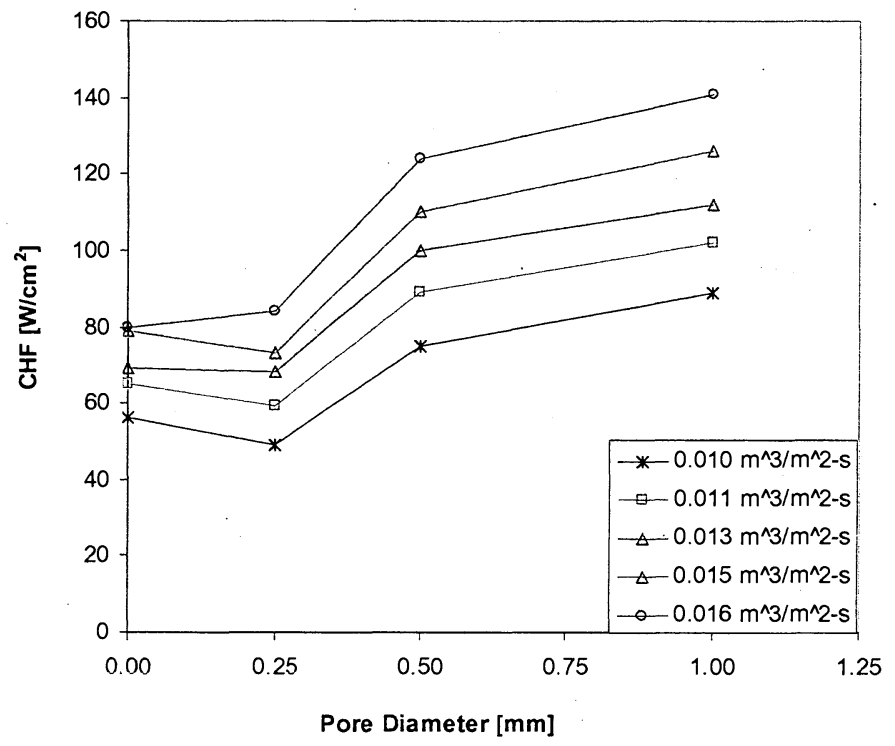

Figure 9. CHF as a Function of Pore Size with Variable Volumetric Fluxes

previously, there was a reduction in heat flux performance for some of the $0.25 \mathrm{~mm}$ pore cases (with the exception of the $0.010 \mathrm{~m}^{3} / \mathrm{m}^{2}$-s volumetric flux case) relative to the flat surface cases. This reduction is clearly shown in the plot as well as in Table 3 through the $\eta_{2-\Phi}$ and $\xi_{2-\Phi}$. It is assumed that for the $0.25 \mathrm{~mm}$ pore case, some liquid is reaching the tunnels. However, below a volumetric flux of $0.016 \mathrm{~m}^{3} / \mathrm{m}^{2}-\mathrm{s}$, the volume entering the tunnels is not significant enough to affect the heat flux. As the pore size increases, more liquid volume reaches the tunnels (specifically for the $0.5 \mathrm{~mm}$ and $1.0 \mathrm{~mm}$ pores) and the heat flux values display a noticeable increase through CHF. Thus pore size may be considered the determining factor for the amount of liquid volume reaching the tunnels as well as heat flux levels attained in the present study. For increasing pore sizes, it is expected that the pores will eventually become sufficiently large such that competition is fostered between the top surface and the tunnels for liquid supply. While phenomena associated with this critical pore diameter was not observed in the present study, future work may include investigation of heat flux performance as a function of the critical pore diameter and the tunnel flooding limit.

\section{CONCLUSIONS}

Spray cooling heat flux measurements were performed on porous tunnel surfaces as well as a flat surface using PF-5060. Tests were performed under nominally degassed conditions (fluid at $41.4 \mathrm{kPa}$ ) for volumetric fluxes ranging $0.010 \mathrm{~m}^{3} / \mathrm{m}^{2}$-s to $0.016 \mathrm{~m}^{3} / \mathrm{m}^{2} \mathrm{~s}$. The nozzle-to-heater surface distance $(17 \mathrm{~mm})$ was held constant for all the tests.

The flat surfaces showed diminishing returns upon the heat flux above a volumetric flux of 0.015 $\mathrm{m}^{3} / \mathrm{m}^{2}$ s. The spray cooling curve for the $0.015 \mathrm{~m}^{3} / \mathrm{m}^{2}-\mathrm{s}$ and $0.016 \mathrm{~m}^{3} / \mathrm{m}^{2}-\mathrm{s}$ cases were nearly identical. Maximum CHF for the flat surface case was $\approx 80 \mathrm{~W} / \mathrm{cm}^{2}$.

The porous tunnel cases with pore diameters of $0.5 \mathrm{~mm}$ and $1.0 \mathrm{~mm}$ each achieved heat fluxes higher than those of the flat surface throughout the spray cooling curves at comparable volumetric fluxes. The 
$0.25 \mathrm{~mm}$ pore case only showed a noticeable increase relative to the flat surface case at a volumetric flux of $0.016 \mathrm{~m}^{3} / \mathrm{m}^{2} \mathrm{~s}$. Both evaporation efficiency and the area utilization factor increased with pore size. For the $0.5 \mathrm{~mm}$ and $1.0 \mathrm{~mm}$ cases evaporation efficiency was greater than that of the flat surface values. For the $0.25 \mathrm{~mm}$ case, evaporation efficiency and area utilization factor held constant or was slightly less than values attained with the flat surface at comparable volumetric fluxes. The highest CHF attained for any of the surfaces tested was for the $1.0 \mathrm{~mm}$ pore surface $\left(141 \mathrm{~W} / \mathrm{cm}^{2}\right)$. At CHF this surface had an evaporation efficiency of $51.1 \%$ and an AUF of 0.69 .

NOMENCLATURE

\begin{tabular}{|c|c|c|c|}
\hline$A$ & Area, $\mathrm{cm}^{2}$ & Greek symbols & \\
\hline$L$ & $\begin{array}{l}\text { distance between successive } \\
\text { structures, } \mathrm{mm}\end{array}$ & $\Gamma$ & $\begin{array}{l}\text { weighted volume flux for } \\
\text { concentric ring, } \%\end{array}$ \\
\hline$P$ & pressure, $\mathrm{kPa}$ & $\eta_{2-\Phi}$ & evaporation efficiency \\
\hline$R_{a}$ & Surface Roughness, $\mu \mathrm{m}$ & & $\dot{q}_{\text {surf }}^{\prime \prime} / \dot{q}_{\text {ideal }}^{\prime \prime}$ \\
\hline $\begin{array}{l}T \\
T C\end{array}$ & $\begin{array}{l}\text { temperature, }{ }^{\circ} \mathrm{C} \\
\text { thermocouple }\end{array}$ & $\xi$ & area utilization factor (AUF) \\
\hline$\dot{V}^{\prime \prime}$ & volume flux, $\mathrm{m}^{3} / \mathrm{m}^{2}-\mathrm{s}$ & & \\
\hline $\begin{array}{l}d 1 \\
d 2\end{array}$ & $\begin{array}{l}\text { pore/dimple diameter, } \mathrm{mm} \\
\text { tunnel diameter, } \mathrm{mm}\end{array}$ & Subscripts & \\
\hline$e$ & error & $i$ & concentric ring \\
\hline$k$ & conductivity, $\mathrm{W} / \mathrm{m}-\mathrm{K}$ & $k$ & conductivity, W/m-K \\
\hline$l$ & nozzle height above heater & $\begin{array}{l}l \\
\max \end{array}$ & $\begin{array}{l}\text { liquid } \\
\text { maximum }\end{array}$ \\
\hline$\dot{q}^{\prime \prime}$ & $\begin{array}{l}\text { surface, } \mathrm{mm} \\
\text { heat flux per unit area, } \mathrm{W} / \mathrm{cm}^{2}\end{array}$ & surf & surface \\
\hline$u$ & heat flux uncertainty, $\mathrm{W} / \mathrm{cm}^{2}$ & $T$ & temperature, ${ }^{\circ} \mathrm{C}$ \\
\hline $\begin{array}{l}x \\
z 1\end{array}$ & $\begin{array}{l}\text { thermocouple distance, } \mathrm{mm} \\
\text { pore/dimple depth into } \\
\text { structure, } \mathrm{mm}\end{array}$ & $2-\Phi$ & $\begin{array}{l}\text { tnermocouple distancc, } \mathrm{m} \\
\text { multiphase }\end{array}$ \\
\hline
\end{tabular}

\section{ACKNOWLEDGMENTS}

This research was supported by the Internal Research and Development Fund at NASA Goddard Space Flight Center. Special thanks is given to Richard Freburger, Jim Dye and Alice Rector of NASA Goddard Space Flight Center, for their test support as well as Parker Hannifin's Gas Turbine Fluid Systems Division (GTFSD) for supplying the spray nozzle.

\section{REFERENCES}

[1] Sehmbey, M., Chow, L., Pais, M., and Mahefkey, T., 1995, "High heat flux spray cooling of electronics," $12^{\text {th }}$ Symposium on Space Nuclear Power and propulsion, Albuquerque, NM, Jan., AIP Conference Proceedings no. 324, pp. 903-909

[2] Yang, J., Pais, M., and Chow, L., 1993, "Critical Heat Flux Limits In Secondary Gas Atomized Liquid Spray Cooling," Experimental Heat Transfer, Vol. 6, pp. 55-67

[3] Estes, K.A., and Mudawar, I., 1995, "Correlation of Sauter mean diameter and critical heat flux for spray cooling of small surfaces," International Journal of Heat and Mass Transfer, Vol.38, No.16, pp. 2985-2996

[4] Yang, J., Chow, L., and Pais, M., 1996, "Nucleate Boiling Heat Transfer in Spray Cooling," Journal of Heat Transfer, Vol. 118, pp. 668-671 
[5] Chen, R-H., Chow, L., and Navedo, J., 2002, "Effects of spray characteristics on critical heat flux in subcooled water spray cooling," International Journal of Heat and Mass Transfer, Vol. 45, pp. 4033-4043

[6] Sehmbey, M., Pais, M., and Chow, L., 1992, "A study of diamond laminated surfaces in evaporative spray cooling," Thin Solid Films, Vol. 212, pp. 25-29

[7] Healy, W., Halvorson, P., Hartley, J., and Abdel-Khalik, S., 1998, "A critical heat flux correlation for droplet impact cooling at low Weber numbers and various ambient pressures," International Journal of Heat and Mass Transfer, Vol. 41, pp. 975-978

[8] Sawyer, M., Jeter, S., and Abdel-Khalik, S., 1997, "A critical heat flux correlation for droplet impact cooling," International Journal of Heat Transfer, Vol. 40, No. 9, pp.2123-2131

[9] Bernadin, J.D., and Mudawar, I., 1999, "The Leidenfrost Point: Experimental Study and Asessment of Existing Models," Journal of Heat Transfer, Vol. 121, pp. 894-903

[10] Pais, M., Chow, L., and Mahefkey, E., 1992, "Surface Roughness and Its Effects on the Heat Transfer Mechanism of Spray Cooling," Journal of Heat Transfer, Vol. 114, No. 1, pp. 211-219

[11] Mudawar, I., and Estes, K., 1996, "Optimizing and Predicting CHF in Spray Cooling of a square surface," Journal of Heat Transfer, Vol. 118, pp. 672-679

[12] Qiao, Y.M., and Chandra, S., 1997, “ Experiments on adding a surfactant to water drops boiling on a hot surface," Proceedings of the Royal Society of London, Vol. 453, pp. 673-689

[13] Qiao, Y., and Chandra, S., 1998, "Spray Cooling Enhancement by Addition of a Surfactant," Journal of Heat Transfer, Vol. 120, pp. 92-98

[14] Mesler, R., 1993, "Surface Roughness and It's Effects on the Heat Transfer Mechanism of Spray Cooling," Journal of Heat Transfer, Vol. 115, pp. 1083-1085

[15] Rini, D., Chen, R.-H., Chow, L., 2002, "Bubble Behavior and Nucleate Boiling Heat Transfer in Saturated FC-72 Spray Cooling," Journal of Heat Transfer, Vol. 124, pp. 63-72

[16] Silk, E.A., Kim, J., and Kiger, K., 2006, "Spray Cooling of Enhanced Surfaces: Impact of Structured Surface Geometry and Spray Axis Inclination," International Journal of Heat and Mass Transfer, Vol. 49, No. $25 / 26$, pp. $4910-4920$

[17] Chien, L.H., and Webb, R.L., 1998b, "A Parametric Study of Nucleate Boiling on Structured Surfaces, Part II: Effect of Pore Diameter and Pore Pitch,” Journal of Heat Transfer, Vol. 120, pp. 1049-1054

[18] Rainey, K.N., Li, G., and You, S.M., 2001," Flow Boiling Heat Transfer From Plain and Microporous Coated Surfaces in Subcooled FC-72," Journal of Heat Transfer, Vol. 123, pp. 918-925

[19] Silk, E.A., Kim, J., Kiger, K., 2006, "Enhanced Surface Spray Cooling with Embedded and Compound Extended Surface Structures," Tenth Intersociety Conference on Thermal and Thermomechanical Phenomena in Electronic Systems, May 30 - June 3, 2006, San Diego, CA. 